\title{
Electromagnetic Guided Factory Intelligent AGV
}

\author{
Xiaoyu Chen ${ }^{1, a}$, Wenping Lin ${ }^{1, b}$, Jian Liü, c, Lichao Guan ${ }^{1, d}$, Yipin Zheng, e, \\ Fengqiang Gao ${ }^{1, \mathrm{f}}$ * \\ ${ }^{1}$ Xiamen University Tan Kah Kee College, Zhangzhou, China \\ a27856512@qq.com, ${ }^{b}$ 2040633748@qq.com, ${ }^{\circ} 547449702 @ q q . c o m, ~{ }^{d}$ 673841868@qq.com,

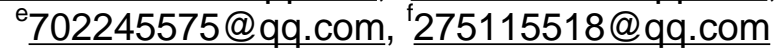

Keywords: Automated Guided Vehicle(AGV), Electromagnetic Guide, RFID Communication, Intelligent Control System

Abstract. In order to realize the automation of factory transport materials, improve the automation level and production efficiency of factories and enterprises, the factory intelligent AGV based on electromagnetic guided was designed and developed. This factory intelligent AGV has tracking guide, RFID communication, wireless module and human-computer interaction, etc. By introducing online site number automatic identification system (RFID), the artificial factor number input errors caused by the site was avoided. By late a lot of test data, technical specifications of factory intelligent AGV is out of standard. The test results show that this intelligent AGV factory is beneficial to improve the production line automation level, and can become the key equipment of automation of logistics transportation.

\section{Introduction}

$\mathrm{AGV}$ is a mobile micro robot with immeasurable development prospects, with functions of planning and decision making, automatic driving, and involves the sensor technology, the microprocessor control, signal processing, motor drive, and many other fields[1-2]. Today, for the enterprise in the fierce competition in the grab a bigger share of the market, we must strengthen production line automation level. Because the AGV automation degree is high, fast action, high efficiency, simple structure, strong controllability, good security advantages, vigorously introduce factory intelligent AGV will become the most desirable measures[3].

This research will apply to factory, reduce the requirement of the staff and improve production efficiency, reduce cost, shorten production cycle, improve production environment and market competitiveness. In addition, the labor cost rising in today's society, this is given priority to with automatic, manual operation and auxiliary equipment will get the favour of the factory. This study begin from the intelligent control system, the realization of the electromagnetic guided AGV, RFID communication, scheduling management, and human-computer interaction, and other functions.

\section{The Operating Principle of Factory Intelligent AGV System}

This study builds the operation principle of the control system of AGV are shown in figure 1[4-5]. 


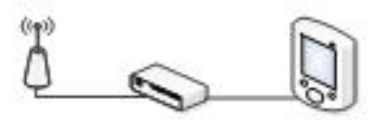

Remote Dispatching System

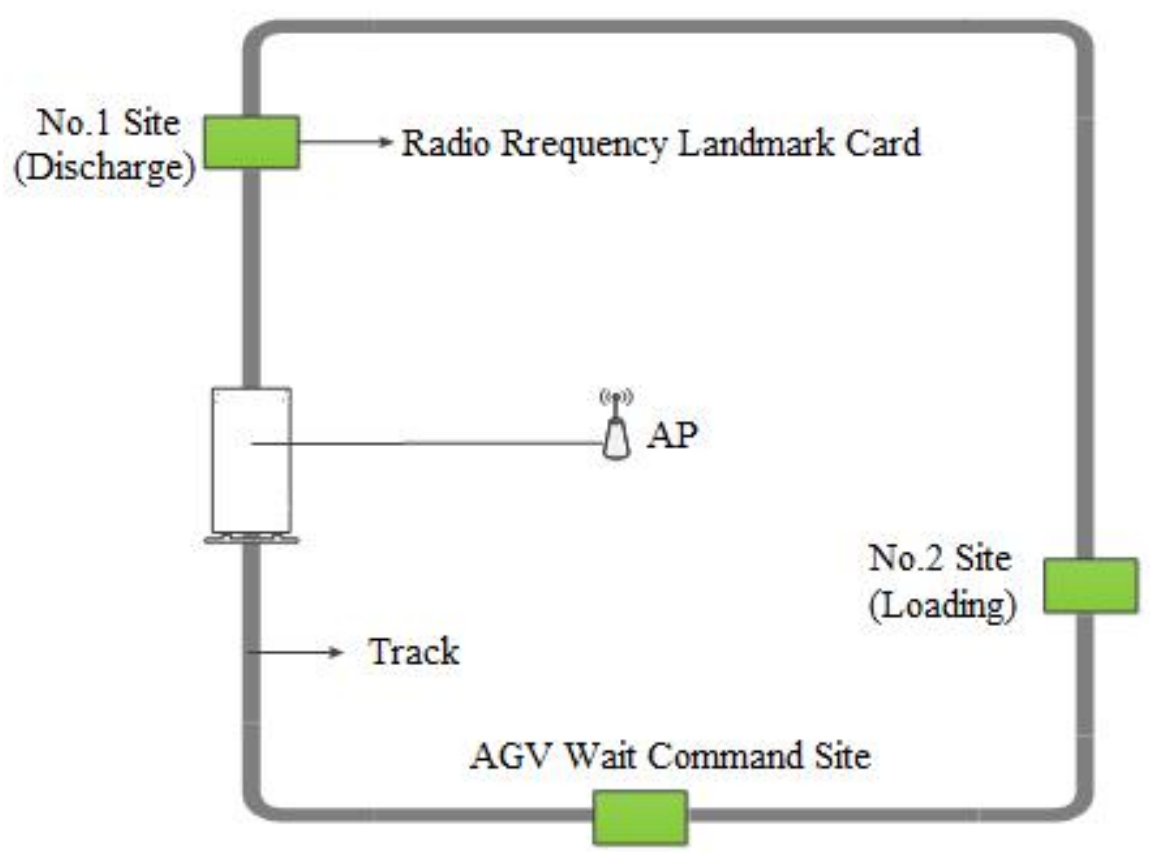

Fig. 1. the principle diagram of the AGV system

The system is mainly composed of intelligent AGV and remote scheduling system. Scheduling system and intelligent car through wireless module for remote communication. Guided AGV in scheduling system, in accordance with the requirements of the homework tasks to choose the optimal path planning by walking through tracking module and RFID accurate dock and appointed place, finally completed a series of tasks, such as pickup, unloading, stop, etc[6-7]. Another AGV path can be adjusted to teach, to adapt to different work environment.

\section{Design of Factory Intelligent AGV}

\section{The Overall Structure of Factory Intelligent AGV System}

The system is mainly composed of intelligent AGV and remote scheduling system. Scheduling system and intelligent car through wireless module for remote communication. Guided AGV in scheduling system, in accordance with the requirements of the homework tasks to choose the optimal path planning by walking through tracking module and RFID accurate dock and appointed place, finally completed a series of tasks, such as pickup, unloading, stop, etc. Another AGV path can be adjusted to teach, to adapt to different work environment. 


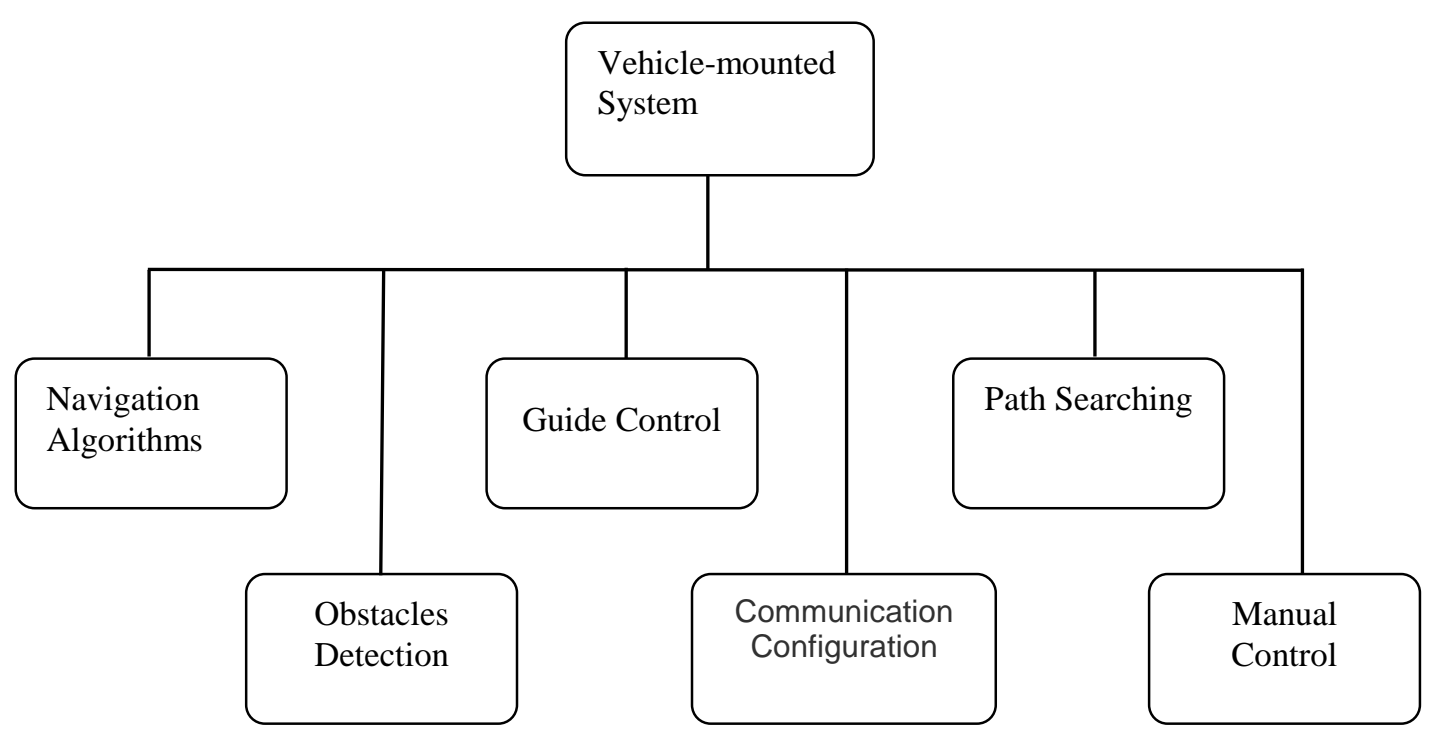

Fig. 2. system function structure drawing

\section{The Hardware Design of Factory Intelligent AGV System}

A key part of the hardware design of the system, including car body, electromagnetic guided rf communication module, safety protection devices, etc. Body part is the basis of the AGV, consists of chassis, chassis, appearance, installed controller, battery and other corresponding module of mechanical device. In normal operation state, AGV car body according to the national standard GB/T20721-2006 guarantee of deformation and torsion is small enough, can avoid the occurrence of dysfunction. And the appearance of the AGV will design the relatively strong security work condition is not dangerous and avoid the collision of human and other equipment cause dysfunction.

Electromagnetic guided by embedding copper wire in the motion of the AGV path, and in copper wire guided by loading frequency and current, based on its identification in order to realize the tracking of the AGV[8]. Its main advantage is hidden, lead pollution and not easily broken, easy to control and communications, no interference of light, the manufacturing cost is low, can make the system can maximize the use in different area.

Radio frequency communication module adopts radio frequency identification technology, through the radio signal to identify specific targets and reading and writing data, using radio waves to communicate[9].

Safety protection device including the console monitor system, emergency stop button and stop button, etc., can guarantee the AGV system in a broad range of situations and AGV surrounding the safety of personnel and equipment operation.

\section{The Software Design of Factory Intelligent AGV Control System}

The software design of the control system of AGV is shown in figure 3[10-11]. Including master control module, obstacle avoidance module, power module, human-computer interaction module, wireless module, RFID module, motor driver module and console. Master control module and each module of the operation of the division of labor to cooperate to complete assignments. 


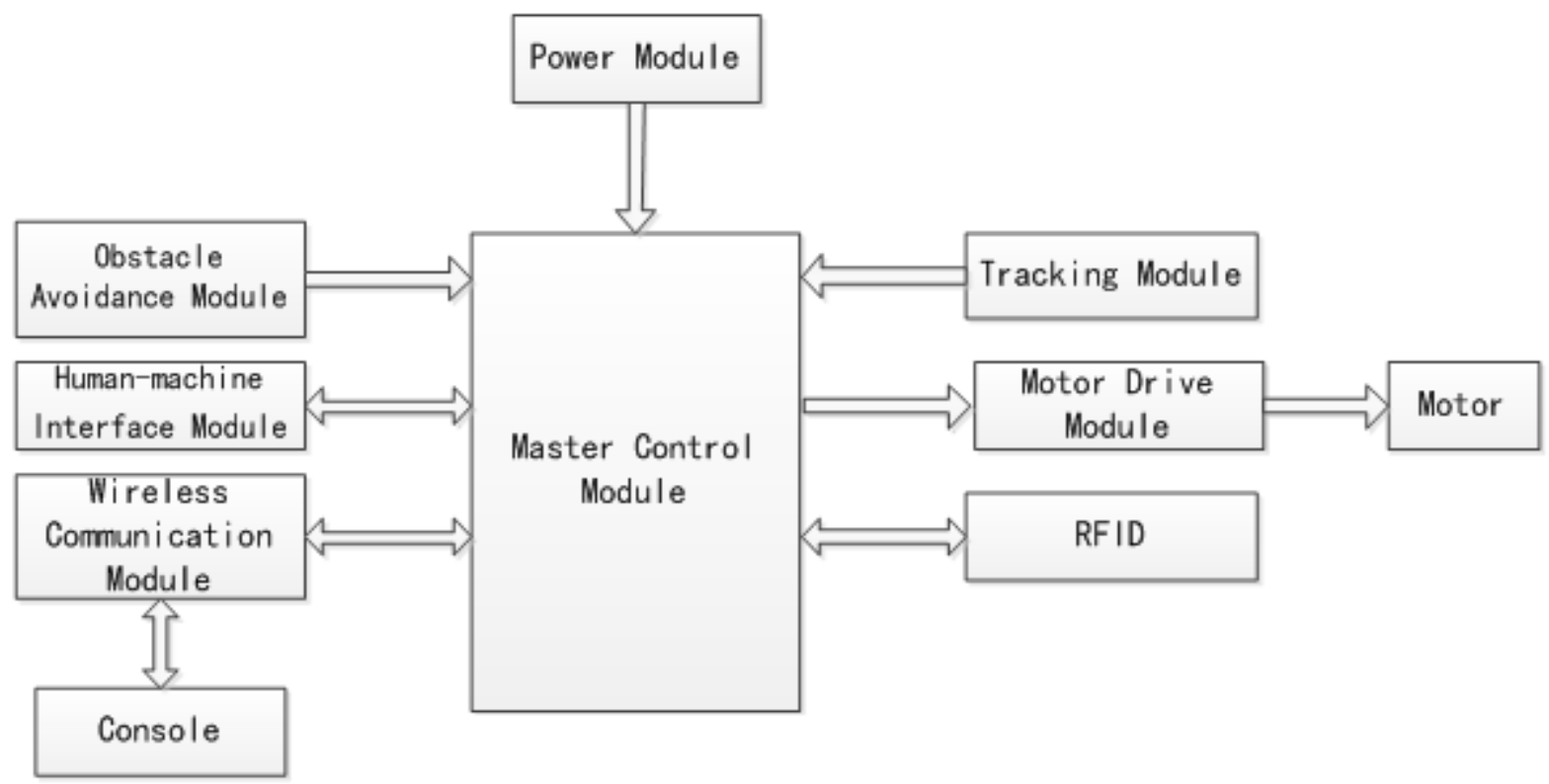

Fig. 3. AGV control system block diagram

RFID communication is the key technology of the system software design. Because of work, usually by human input AGV current online login site number, easy to cause the site number of input errors, in order to avoid errors caused by human factors, the AGV system introduced the online site number automatic identification (RFID) system. Radio frequency (RF) coordinates by tuning into the radio frequency electromagnetic fields to send radio signals, magnetic navigation AGV online login, need to know the current point the location of the logo. AGV need online login, AGV through the site, near the site number and stay for this site can be read automatically during the unloading site, so as to avoid site number input errors.

\section{Performance Test Results of Factory Intelligent AGV}

For that factory intelligent AGV performance, get detailed technical specifications and parameters, the design of the intelligent AGV factory hardware debugging and equipment debugging. Hardware debugging, for all the functional modules one by one on the circuit board debugging. Module test as shown in figure 4.

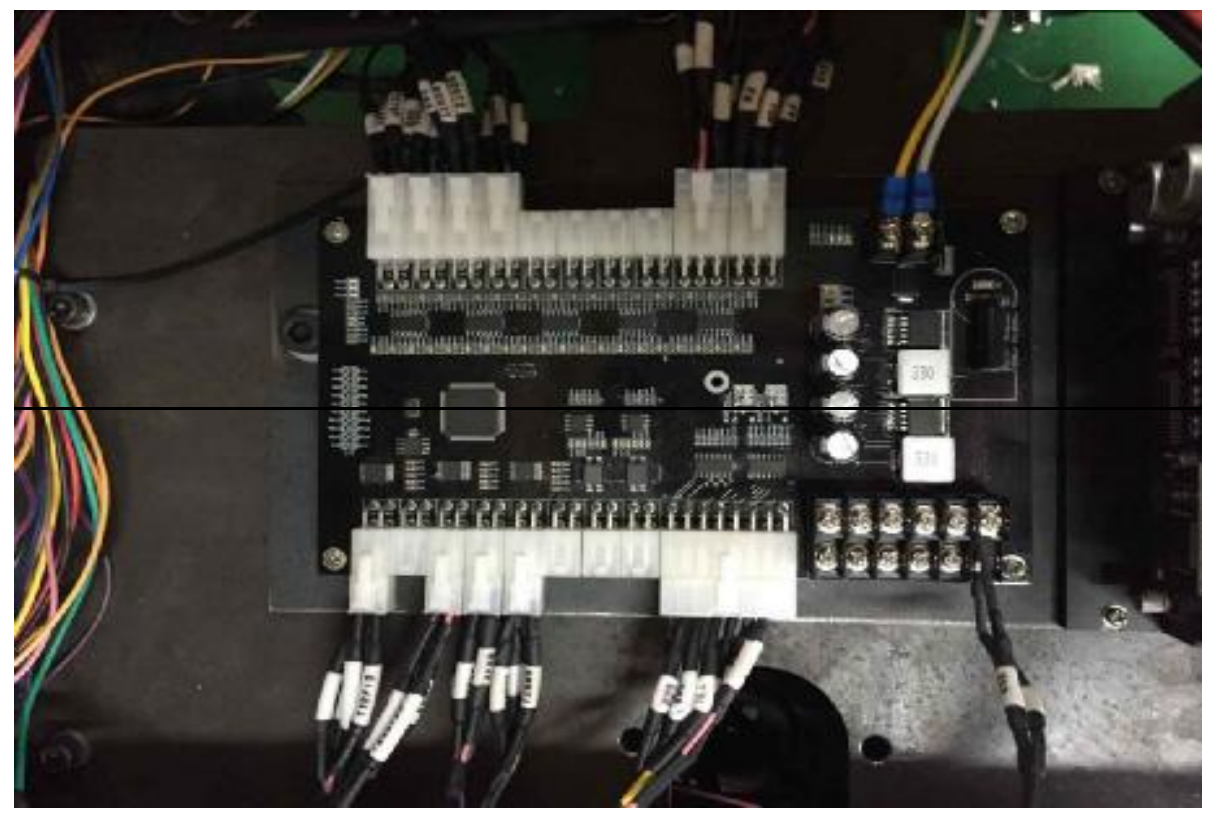

Fig. 4. module test 
After the completion of the hardware debugging, AGV machine debugging, first of all, the deviation between test and the specification parameters; Then update the performance data of running status of $\mathrm{AGV}$, if do not meet the requirements, design parameters analysis of internal modules need to debug and overall architecture changes; Finally optimization can be adjusted to enhance the performance of the components, such as the body the bearing capacity, tracking optimization of reaction time, degree of obstacles. By the late a lot of testing data specification of detailed parameter in the following table 1, that led to the large-scale production workshop production of the late data support.

Table 1. factory intelligent AGV specification parameters

\begin{tabular}{|c|c|}
\hline \multicolumn{2}{|r|}{ Technical Specification Parameter } \\
\hline Item & Basic Parameter \\
\hline AGV Name & Bidirectional knapsack type automatic guiding trolley \\
\hline Delivery Mean & Bidirectional knapsack \\
\hline Guided Mode & Magnetic stripe guide: S-pole \\
\hline Drive Mode & Two rounds of differential drive \\
\hline $\begin{array}{l}\text { Minimum Turning } \\
\text { Radius }\end{array}$ & $500 \mathrm{~mm}$ \\
\hline Running Speed & 0-40m/min（Adjustable ) \\
\hline Walking Function & $\begin{array}{l}\text { Forward, backward, acceleration, deceleration, turning, } \\
\text { pause, selection of fork in the road, etc. }\end{array}$ \\
\hline Control Mode & Automatic Tracking Control \\
\hline Landmark way & PFRID Internet of things technology control \\
\hline Stop Accuracy & $\pm 5 \mathrm{~mm}$ \\
\hline $\begin{array}{l}\text { The biggest bear } \\
\text { carrying }\end{array}$ & $200 \mathrm{~kg}$ \\
\hline Power Supply Mode & DC $24 \mathrm{~V}$ \\
\hline accumulator capacity & 38Ah \\
\hline Endurance Time & $\geq 12 \mathrm{~h}$ \\
\hline Battery & Two $38 \mathrm{Ah} 12 \mathrm{~V}$ batteries in series \\
\hline Charging Mode & Offline charging \\
\hline $\begin{array}{l}\text { human-computer } \\
\text { interface }\end{array}$ & DGUS touch screen in serial port \\
\hline safety protection & $\begin{array}{l}\text { Obstacle avoidance sensor, collision avoidance sensor, } \\
\text { emergency stop button }\end{array}$ \\
\hline Power alarm & $\begin{array}{c}\text { When the charge is less than } 22.5 \mathrm{~V} \text { when prompted to } \\
\text { charge }\end{array}$ \\
\hline $\begin{array}{l}\text { Failure or obstacle } \\
\text { warning }\end{array}$ & Music alarm, three lights flash to remind \\
\hline
\end{tabular}

\section{Conclusions}

In this paper, the development of intelligent AGV factory mainly used in the factory workshop. Because of the uniqueness of the factory, has the characteristics of streamline repetitive operation, 
very suitable for the operation of the product that is in accordance with the planned route to transport the goods accurately cycle. This research mainly implements the electromagnetic guided, RFID communication and multilevel security alarm mechanism, can read and write through the radio signal to identify specific targets and related data, also can ensure the AGV system in all situations and AGV surrounding the safety of personnel and equipment operation, has the function of innovation significance and practical value. At present, the AGV system has been completed and architecture development and complete can improve the operation of the specific product, may at any time by the mass production. Research also found that in the process of the project and shortcomings. Daily wear and tear, navigation way vulnerable to loop through the metal mechanical damage effect of the hard objects such as the navigation accuracy. Hardware requirements, the manufacturing cost is higher, the accuracy and reliability of the guidance is closely related to the manufacturing precision of the gyroscope and the service life. From the fit between hardware, lubrication degree and finding the best alternative to solve the above problems, are all can be deep and future research directions. Believe that with the development of technology will continue to overcome the shortcomings perfect technology, make the factory intelligent AGV popularization and development of faster.

\section{References}

[1] Zhi Shen. Introduction to automatic guided vehicle (AGV) technology development [J]. Science and technology plaza, 2008, 12:232-233.

[2] Hong Guan, Zhiyong Zhang, Wenhua Yang. AGV whole integrated system structure design [J]. Journal of Logistics Technology, 2004 (4):37-38.

[3] Die Hu. Automatic DaoYinChe (AGV) research and design of the control system [D]. Hubei university of technology, 2014.

[4] Xiangyuan Huang. Automatic guided vehicle control system [J]. Journal of light industrial machinery, 2012, 02:38-41.

[5] Shuyuan Li. Introduction to the automatic pilot run the car delivery system (AGV) [J]. Science and technology, 2010, 29:94-95.

[6] Lin Yang. RFID system safety evaluation and protection technology [M]. Electronic Industry Press, 2015.

[7] Jianliang Gao. Principle and technology [M]. IOT RFID Electronic Industry Press, 2013.

[8] Chidong Zhou.The key technology and application of magnetic navigation automated guided vehicle(AGV)[D]. Nanjing university of aeronautics and astronautics, 2012.

[9] RF world magazine editorial board. Chinese Journal of Semiconductors[M].RF World,2009.

[10] Jun Liu. Example of STM32 (the second version) [M]. Beijing University of Aeronautics and Astronautics Press, 2014.

[11] Honggui Wu, Jiali Li, Liang Li. PC application development comprehensive practice [M]. Neusoft Electronic Publishing House, 2013. 